\title{
Comparison Performances of EDM on Ti6Al4V with Two Graphite Grades
}

\author{
Apiwat Muttamara
}

\begin{abstract}
Technologies for EDM machining are demanded in many industrial fields. Graphite is widely used as electrode material in EDM. Graphite (Poco EDM-3) and copperinfiltrated-graphite (Poco EDM-C3) electrodes were used to compare the corresponding to EDM properties. The experiments were carried out on Ti6Al4V. Performance in respect to MRR and electrode wear is compared for two graphite qualities. The results show that EDM3 graphite performs very well giving significantly higher MRR than EDM-C3, and also with acceptable relative electrode wear. The surface roughness of workpiece produced by EDM-C3 is better than EDM-3 due to gap distance of EDM-C3 is larger than that produced by EDM-3. The two electrode materials give the same micro-hardness of the layers that are about $800 \mathrm{HV}$.
\end{abstract}

Index Terms-EDM, graphite electrode, Ti6Al4V, copperinfiltrated-graphite.

\section{INTRODUCTION}

Electrical discharge machining (edm) is recognized as a precision machining process for hard materials [1]-[3]. However, titanium alloys are also regarded as "difficult-tomachine" materials because of their outstanding properties such as a high strength-to-weight ratio, good resistance to creep and fatigue and excellent corrosion resistance. They are increasingly being used in the following areas: aerospace applications, automotive applications, biomedical applications and other industries [4]. Graphite is widely used as electrode material in edm, this is due to its low density and good electrical along with its machinability [4], [5]. As a thermal erosion process, electrical discharge machining (edm) is capable of machining all electrically conductive materials irrespective of their hardness. the temperature of the plasma $(>10,000 \mathrm{k})$ during the discharging process is much higher than the melting point of all materials [3]. Therefore, the edm process offers to machine titanium alloys This paper presents performance of graphite (poco edm-3) and copper-infiltrated-graphite (poco edm-c3) electrodes, and the influence of edm parameters on material removal rate, electrode wear. The grades were selected by recommendations which speed and surface finish are considered. performances of edm and qualities of workpiece are depend on graphite grades based on the grain size, density and mechanical and electrical properties. the finer grades with smaller grains and less porosity, offering lower electrode wear, higher mechanical strength but giving somewhat lower mrr compared to coarser grained grades [5],

Manuscript received October 28, 2014; revised December 18, 2014.

Apiwat Muttamara is with the Faculty of Engineering, Thammasat University, Pathumthani, Thailand (e-mail: mapiwat@engr.tu.ac.th).
[6]. The performance which were considered in respect to mrr and electrode wear. The parameters which were considered as relevant to surface roughness. furthermore, effects of phenomena were investigated via gap distance and hardness of white layer.

\section{EXPERIMENTAL PROCEDURE}

The experiments were conducted using Mitsubishi Electric Automation (EA8 - ADVANCE SERIES). The used workpiece was Ti6Al4V. Table I shows chemical compositions of Ti6Al4V. Electrodes were compared with EDM-3 and EDM-C3 from POCO Graphite, Inc. The diameter of the electrode was $3 \mathrm{~mm}$ and a depth of cut was 3 $\mathrm{mm}$. EDM-3 is an isotropic, ultrafine grain graphite and EDM-C3 is a high quality graphite infiltrated with copper Positive polarity was selected for an electrode due to it gives more efficient than negative polarity [7], [8]. Table II presents the physical properties of electrode materials in this experiment. Graphite used in positive polarity leads to wear rates approximately $10 \%$ to $50 \%$ in finish mode (with a current intensity less than $5 \mathrm{~A}$ ) and about $0 \%$ in roughing mode(current intensity greater than 25A) [5]. Table III presents EDM conditions.

TABLE I: CHEMICAL COMPOSITIONS OF A WORKPIECE

\begin{tabular}{|l|c|}
\hline Elements & $(w t \%)$ \\
\hline $\mathrm{Al}$ & 6 \\
\hline $\mathrm{Fe}$ & Max 0.25 \\
\hline $\mathrm{O}$ & Max 0.20 \\
\hline $\mathrm{Ti}$ & 90 \\
\hline $\mathrm{V}$ & 4 \\
\hline
\end{tabular}

TABLE II: Properties EleCtrode MATERIALS

\begin{tabular}{|l|c|c|}
\hline \multirow{2}{*}{\multicolumn{1}{|c|}{ Properties }} & \multicolumn{2}{c|}{ Materials } \\
\cline { 2 - 3 } & EDM-3 & EDM-C3 \\
\hline Particle size $(\mu \mathrm{m})$ & $<5$ & $<5$ \\
\hline Density $\left(\mathrm{g} / \mathrm{cm}^{3}\right)$ & 1.81 & 3.25 \\
\hline Melting point $\left({ }^{\circ} \mathrm{C}\right)$ & 3,350 & 1,100 \\
\hline Electrical Resistance $(\mu O h m-i n)$ & 615 & 127 \\
\hline
\end{tabular}

\section{RESULTS AND DISCUSSION}

The effect of a graphite electrode was tested by evaluating the MRR and EWR. First, the experiment was set with discharge current $12 \mathrm{~A}$ and discharge duration or on time $\left(t_{e}\right)=200 \mu \mathrm{s}$ using normal graphite electrode (EDM-3).

TABLE III: EDM CONDITIONS

\begin{tabular}{|l|l|}
\hline \multicolumn{2}{|c|}{ Levels } \\
\hline Polarity & Positive \\
\hline Open Load Voltage (Volts) & 250 \\
\hline Current $(\mathrm{A})$ & $6,12,25$ \\
\hline Discharge duration $(\mu \mathrm{s})$ & $100-300$ \\
\hline Duty Factor $(\%)$ & $30,50,70$ \\
\hline
\end{tabular}


Fig. 1 shows the effect of duty factor to removal rate (MRR) and electrode wear ratio (EWR). The duty factor (D.F.), which means the ratio between the pulse duration $t_{e}$ $[\mu \mathrm{s}]$ and the pulse cycle time $\mathrm{t}_{\mathrm{o}}[\mu \mathrm{s}]$. Smaller values of duty factor would lead to very low discharges frequency consequently decreasing the material removal rate. Another important aspect regarding the choice of small values of duty factor is associated with the low level of contamination across the working gap. According to some concentration of sub-microscopic particles, fibers or moisture drops in the working gap can be reduced because these particles arrange themselves in such a way that a kind of bridge may occur intensifying the electric field, which by its turn quickly fires another discharge [9]. The highest MRR was obtained when using $50 \%$ of duty factor. And also, the lowest electrode wear ratio was gotten at this duty factor. For higher duty factor than $50 \%$, it was noticed that much instability was brought into the working gap in either the form of arc discharge pulses or short-circuit pulses, probably due to insufficient interval time to successive discharges to evacuate the coarse eroded material and simultaneously deionize the working gap. As a consequence the overconcentration of dielectric and electrodes byproducts negatively interfered on the occurrence of normal discharges, causing by this time wear of the electrodes related to the poor dispersion of discharges along the electrode frontal surfaces, as well as low performance of the electrical discharge machining [10].

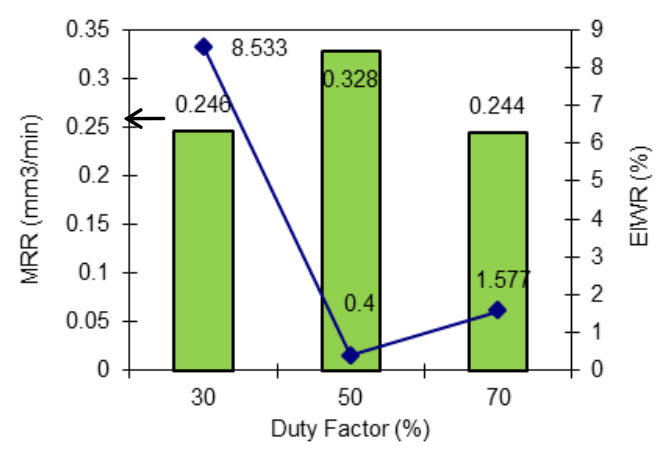

Fig. 1. Relationship of material removal rate and electrode wear ratio versus duty factor. ( $\left.I=12 \mathrm{~A}, t_{e}=200 \mu \mathrm{s}\right)$.

Effect of discharge current on MRR and EWR can be seen in Fig. 2. The experiment was set at $t_{e}=200 \mu \mathrm{s}$, and Duty factor $(D F)=50 \%$. The MRR increased with increasing of discharge current but MRR was dropped when discharge current $=25$ A. Both EDM-3 and EDM-C3 are same trend. The highest MRR and minimal wear were obtained using EDM-3 at discharge current= $12 \mathrm{~A}$. The results of electrode wear ratio relate to melting point; materials with higher melting points wear less. However, the wear ratio is inversely proportional to the MRR result. In the case of lower MRR, the electrode must spend more time to achieve machining.

From the results of Fig. 1 and Fig. 2, the MRR can be obtained when using discharge current $=12 \mathrm{~A}$ and $\mathrm{DF}=50 \%$. Fig. 3 shows effect of discharge duration on MRR and EWR. Discharge duration directly influence the machining However, the impact of discharge current is limited by the electrode surface area [11]. For EDM-C3, electrode wear ratio decrease inverse proportional to discharge duration.
The highest MRR and minimal wear were obtained using EDM-3 at discharge duration $=200 \mu \mathrm{s}$. The MRR was the highest for a medium range set up of discharge duration. Due to the short pulse causes less energy, whereas long pulse duration causes more energy. However, the results of experimental investigation show that for every discharge current there is corresponding optimal pulse duration which allows maximum material removal rate. The exceeding of the discharge duration causes less energy density on the workpiece and loses chance of the machining performance. Because the EDM process also needs explosion for eliminating debris during pulse duration.

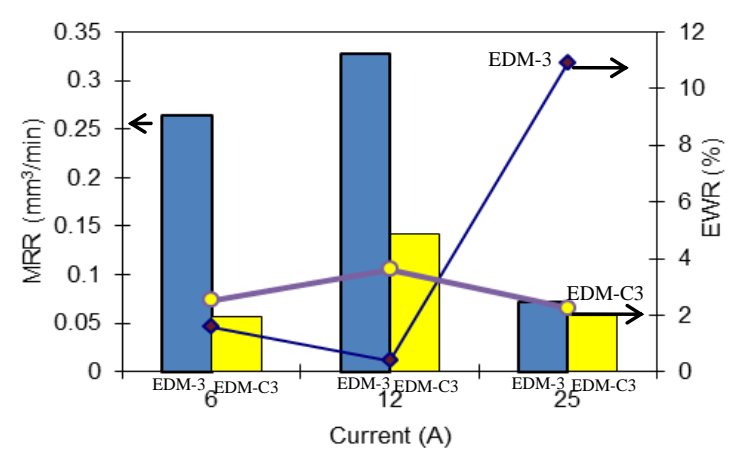

Fig. 2. Relationship of material removal rate and electrode wear ratio versus discharge current. $\left(t_{e}=200 \mu \mathrm{s}, D F .=50 \%\right)$.

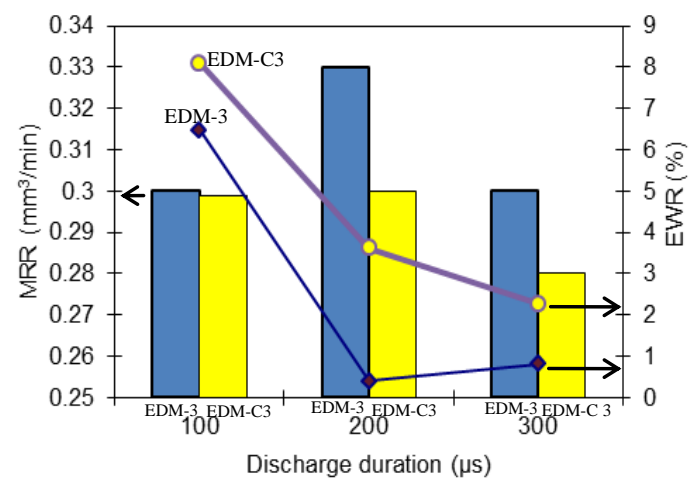

Fig. 3. Relationship of material removal rate and electrode wear ratio versus on time. $(I=12 \mathrm{~A}, D F .=50 \%)$.

The surface was investigated by cross-sectional SEM. Fig. 4 shows SEM micrographs of white layers created by a) an EDM-3 electrode and b) an EDM-C3 electrode. From the images two different shaded phases are clearly identified. It has been found that for two graphite grades. Thickness of white layers are quite same, they are about 20-35 $\mu \mathrm{m}$. Some porosity and cracks are visible on the deposited layer as dark mark in the coated region. This phenomenon is more prominent for the coating deposited with carbon from graphite in electrodes and kerosene. The EDM process vaporizes the dielectric medium and during deposition process this vaporized dielectric may trapped inside the coating. Further, with semi-sintering of the tool electrode, coarseness of surface layer increases compared to a solid electrode. The workpiece and electrode were melted and cooled at high speed [12]. This layer is crystal brittle materials cause crack generation. The variation in surface roughness with different discharge current for two electrode materials is shown in Fig. 5. Normally, the Ra value was more when increasing in discharge current [13]. Due to discharge energy results in larger crater on the surface. 
However the higher discharge current may cause lower surface roughness because this condition was used for discharge duration for $200 \mu$ s. If discharge current is too low, discharge process may not occur perfectly, the process probably causes short discharge. From the Fig. 5, the EDM$\mathrm{C} 3$ gives a little better surface roughness than EDM-3 on all EDM conditions. It can be explained that some infiltrated copper in EDM-C3 was easier melted than normal carbon in graphite electrode during discharge process. When thermal generated from discharge heat up to normal temperature 8,000- 12,000 C of discharge [14]. EDM-3 cannot be reached over than $1,100 \mathrm{C}$ due to its melting point. But EDM-3, the thermal can be reached to $3,350{ }^{\circ} \mathrm{C}$. Consequently, the thermal of discharging from EDM-C3 is less than from EDM-3 electrode. This phenomena can explain MRR, EWR and surface roughness. Electrode shapes during EDM process are shown in Fig. 6, they were observed at 15 minutes of machining time. The corner wear of EDM-C3 is more obtained than EDM-3. It relates to melting point of the electrode. Micro-hardness of the coating surfaces were measured by Vickers' micro-hardness tester with $10 \mathrm{~g}$ load and 10 seconds of dwell time. Microhardness distribution on the cross section of the white layers EDMed with two electrodes were plotted from the top of the surface into the substrate shown in Fig. 7. (EDM conditions: Ie $=12 \mathrm{~A}$, discharge duration $=200 \mu \mathrm{s}$ ). From the plot it is observed that hardness value of both graphite grades are quite same. The average thickness of the both white layers are about $25 \mu \mathrm{m}$. The hardness values at the top surface of the white layer are in the range of $720 \mathrm{HV}$ to $800 \mathrm{HV}$. The hardness may belong to $\mathrm{TiC}$ which was generated from an electrode material and carbon from dielectric fluid [15]-[19]. Normally, there are three zones on the workpiece when discharge on a steel: The white layer is on the top layer follows Heat Affected Zone (HAZ) and matrix [12], [13].

a) EDMed with EDM-3

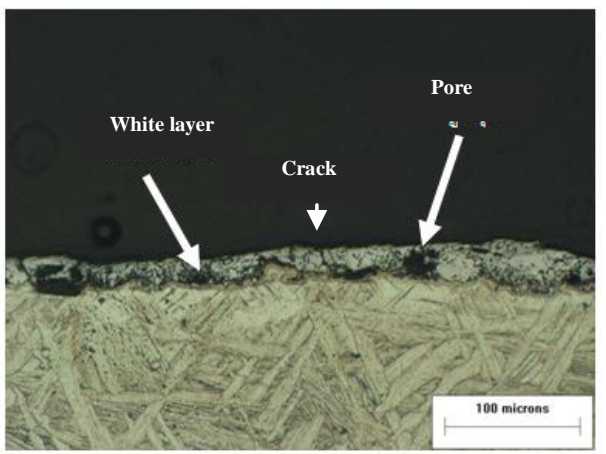

b)

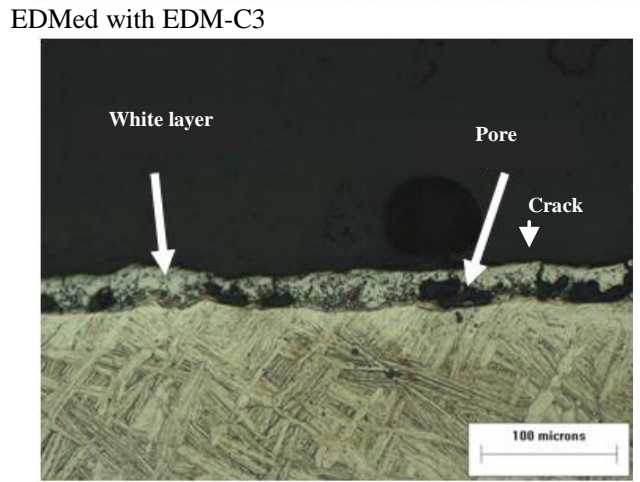

Fig. 4. Cross section polishes of EDMed workpieces with EDM-3 and b) EDM-C3.

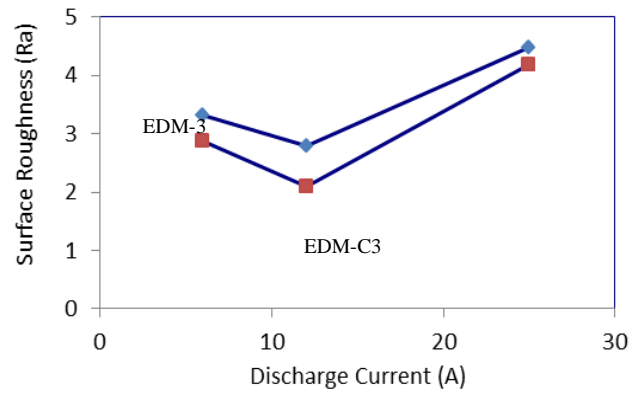

Fig. 5. Relationship between surface roughness and discharge current.
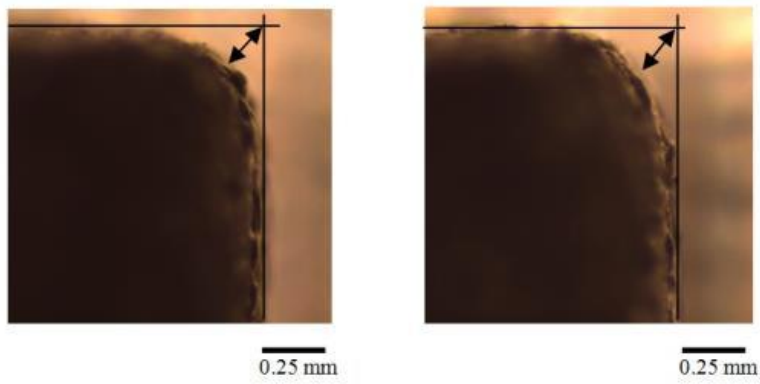

Fig. 6. Electrode shapes obtained after EDM process; a) EDM-3 and b EDM-C3

In case of an alloy metal, Ti6Al4V, the zone under the white layer is not affect from the discharge energy so the micro-hardness is same as hardness of a workpiece (about $260 \mathrm{HV})$

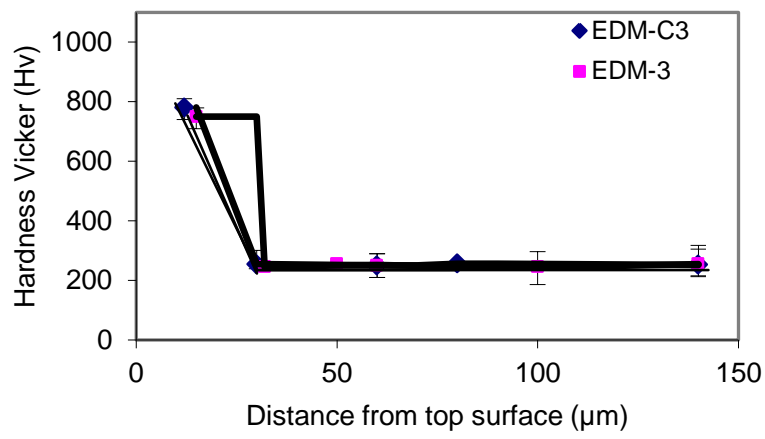

Fig. 7. Hardness Vicker of cross sectional EDMed workpiece with EDMC3 and EDM-3.

\section{CONCLUSION}

In the EDM of Ti6Al4V with EDM-3 and EDM-C3, the obtained results are summarized as follows:

1) The MRR is larger when using EDM-3, and the EWR is smaller compared to EDM-C3.

2) EDM-C3 gives better surface roughness of workpiece than produced by EDM-3.

3) EDM process gives value in hardness of the white layer up to 3 to 4 times ( $720-800 \mathrm{HV}$ ) compared to Ti6Al4V substrate.

\section{ACKNOWLEDGMENT}

The author thanks the research supporting grant from Thammasat University's research fund and the National Research University Project of Thailand Office of Higher Education Commission. 


\section{REFERENCES}

[1] W. Koenig, D. F. Dauw, G. Levy, and U. Panten, "EDM future steps towards the machining of ceramics," Ann. CIRP, vol. 37, no. 2, pp. 625-631, 1998.

[2] T. Masuzawa, "State of the art of micromachining," Ann. CIRP Manufacturing Technology, vol. 49, pp. 473-488, 2004.

[3] N. Mohd Abbas, D. G. Solomon, and Md. F. Bahari, "A review on current research trends in electrical discharge machining (EDM)," International Journal of Machine Tools and Manufacture, vol. 47, pp. 1214-1228, 2007.

[4] S. Plaza, J. A. Sanchez, and E. Perez, el al., "Experimental study on micro EDM-drilling of Ti6Al4V using helical electrode," Precision Engineering, vol. 38, issue 4, pp. 821-827, 2014.

[5] L. Kristian, "Performance of two graphite electrode qualities in EDM of seal slots in a jet engine turbine vane," J. Mater. Process. Technol, vol. 149, issue 1-3, pp. 152-156, 2004.

[6] A. Muttamara, Y. Fukuzawa, N. Mohri, and T. Tani, "Effect of electrode material on electrical discharge machining of alumina," J. of Mater. Processing Technology, vol. 209, issue 5, pp. 2545-2552, 2009.

[7] W. König, R. Wertheim, and Y. Zvirin, Ann. CIRP, vol. 24, pp. 95, 1975.

[8] D. D. Dibitonto, P. T. Eubank, M. R. Patel, M. A. Barrufet, J. Appl. Phys., vol. 66, p. 4095, 1989.

[9] Y. S. Liao, P. S. Wu, and F. Y. Liang, "Study of Debris Exclusion Effect in Linear Motor Equipped Die-sinking EDM," Procedia CIRP, vol. 6, pp. 123-128, 2013.

[10] P. Fonda, Z. Wang, K. Yamazaki, and Y. Akutsu, "A fundamental study on Ti-6Al-4V's thermal and electrical properties and their relation to EDM productivity," Journal of Materials Processing Technology, vol. 202, issue 1-3, pp. 583-589, 2008.

[11] M. Gostimirovic, P. kovac et al., "Effect of electrical pulse parameters on the machining performance," Indian Journal of Engineering \& Materials Sciences, vol. 18, pp. 411-415, 2012.

[12] S. Kumar, R. Singh, T. P. Singh, and B. L. Sethi, "Surface modification by electrical discharge machining: A review article," Journal of Materials Processing Technology, vol. 209, issue 8, pp. 3675-3687, 2009.
[13] Y. Zhang, Y. Liu, Y. Shen, R. Ji, Zhen Li, and Chao Zheng, "Investigation on the influence of the dielectrics on the material removal characteristics of EDM," Journal of Materials Processing Technology, vol. 214, issue 5, pp. 1052-1061, 2014.

[14] B. Geoffrey and W. A. Knight, Fundamentals of Metal Machining and Machine Tools, Marcel Dekker, Inc., New York, 1989, p. 491.

[15] S. Chakraborty, V. Dey, and S. K. Ghosh, "A review on the use of dielectric fluids and their effects in electrical discharge machining characteristics," Precision Engineering, 2014, in press.

[16] S. Singh, S. Maheshwari, and P. C. Pandey, "Some investigations into the electric discharge machining of hardened tool steel using different electrode materials," J. Mater. Process. Technol, vol. 149, pp. 272$277,2004$.

[17] S. Singh, A. Bhardwaj, "Review to EDM by Using Water and Powder-Mixed Dielectric Fluid," Journal of Minerals \& Materials Characterization \& Engineering, vol. 10, no. 2, pp. 199-230, 2011.

[18] V. Senthilkumar and B. U. Omprakash, "Effect of Titanium Carbide particle addition in the aluminium composite on EDM process parameters," Journal of Manufacturing Processes, vol. 13, issue 1, pp. 60-66, 2011.

[19] P. Janmanee and A. Muttamara, "Surface modification of tungsten carbide by electrical discharge coating (EDC) using a titanium powder suspension," Applied Surface Science, vol. 258, pp. 7255$7265,2012$.

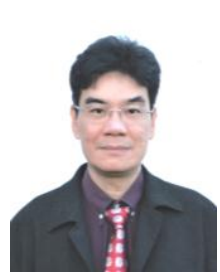

Apiwat Muttamara is an assistant professor of the Department of Industrial Engineering at Thammasat University, Thailand. He was born in Bangkok, Thailand. He received his bachelor in industrial engineering from Kasetsart University, Bangkok, Thailand and the doctoral engineering in materials science from Nagaoka University of Technology, Niigata, Japan. He is interested in electrical discharge machining, especially EDM on an insulating material. 